\title{
НОВЫЕ СВЕДЕНИЯ О РАННЕЙ ИСТОРИИ АНДРОНОВСКИХ ПЛЕМЕН ЦЕНТРАЛЬНОГО КАЗАХСТАНА (по материалам кургана 7 могильника Талдинский-1)
}

\author{
(С) 2018 г. С.У. Жауымбай, И.А. Кукушкин, А.И. Кукушкин, \\ Е.А. Дмитриев, О.С. Шохатаев
}

В статье в научный оборот вводятся материалы кургана 7 могильника Талдинский-1. Исследования проводились археологической экспедицией КарГУ им. Е.А. Букетова в 2018 г. Памятник находится в 93 км юго-восточнее г. Караганды, в 12 км к ВСВ от п. Талды и расположен на относительно ровной площадке левобережья p. Талды (Шетский р-н, Карагандинская обл.). Здесь визуально зафиксировано 18 сооружений двух культурно-хронологических горизонтов: раннеандроновского (петровского/раннеалакульского типа) и позднебронзового (бегазы-дандыбаевского типа). Керамический материал исследованного сооружения, по мнению авторов, характеризует ранний этап петровской культуры. Получены новые сведения о ранней истории андроновских племен на территории Центрального Казахстана. В противовес устоявшемуся мнению о наличии в регионе только памятников позднего этапа петровской культуры, выдвигается аргументированное предположение, о том, что накопленные материалы представляется возможным разделить на два этапа: ранний (собственно петровский) и поздний (аналогичный кулевчинскому), что отражено в керамическом комплексе и инвентаре.

Ключевые слова: археология, Центральный Казахстан, эпоха бронзы, петровская культура, наконечник копья, керамический комплекс, ритуальный сосуд

Ранняя история андроновских племен Центрального Казахстана, несмотря на изученность значительного количества памятников, остается в достаточной мере гипотетичной. Выявленный за предыдущие годы пласт наиболее древних комплексов бронзового века региона (Ащису, Нуртай, Бозенген, Аяпберген, Икпень I и др.) [Ткачев А.А., 2002; Кукушкин И.А., 2006; 2011] объединен наличием керамических сосудов с ребристым плечом. Несмотря на их сходство с северо-казахстанскими памятниками петровского типа, в настоящее время, имеются две гипотезы их генезиса. Согласно доминирующему представлению, появление данных комплексов в Центральном
Казахстане вызвано миграцией носителей петровской культуры (И.А. Кукушкин) [Кукушкин И.А., 2011, с. 109; Кукушкин И.А., Дмитриев, 2018, с. 36]. Иная модель предложена А.А. Ткачевым, считающим, что этот ранний пласт памятников (нуртайская культура) является продуктом имманентного развития автохтонного населения, а некоторая близость обоих блоков комплексов обусловлена единой степной подосновой [Ткачев А.А., 1999, с. 27-28], что было резонно подвергнуто критике [Ткачев В.В., 2007a].

В рамках данной статьи предлагается обратиться к вопросу о появлении петровских комплексов в регионе на материалах кургана 7 
могильника Талдинский-1, раскопанного в 2018 г. Памятник находится в Шетском районе Карагандинской области, в 93 км юго-восточнее г. Караганды, в 12 км к ВСВ от п. Талды, в 9 км северо-западнее п. Байбала, в 2,5 км к ЗС3 от п. Жанажурт и расположен на относительно ровной площадке левобережья р. Талды. На погребальной площадке, вытянутой с запада на восток, визуально зафиксировано 18 сооружений двух культурно-хронологических горизонтов: андроновского (петровского/ раннеалакульского типа) и позднебронзового (бегазы-дандыбаевского типа) (рис. 1).

Сооружение 7 до раскопок представляло собой оплывший земляной курган, в полах насыпи которо-

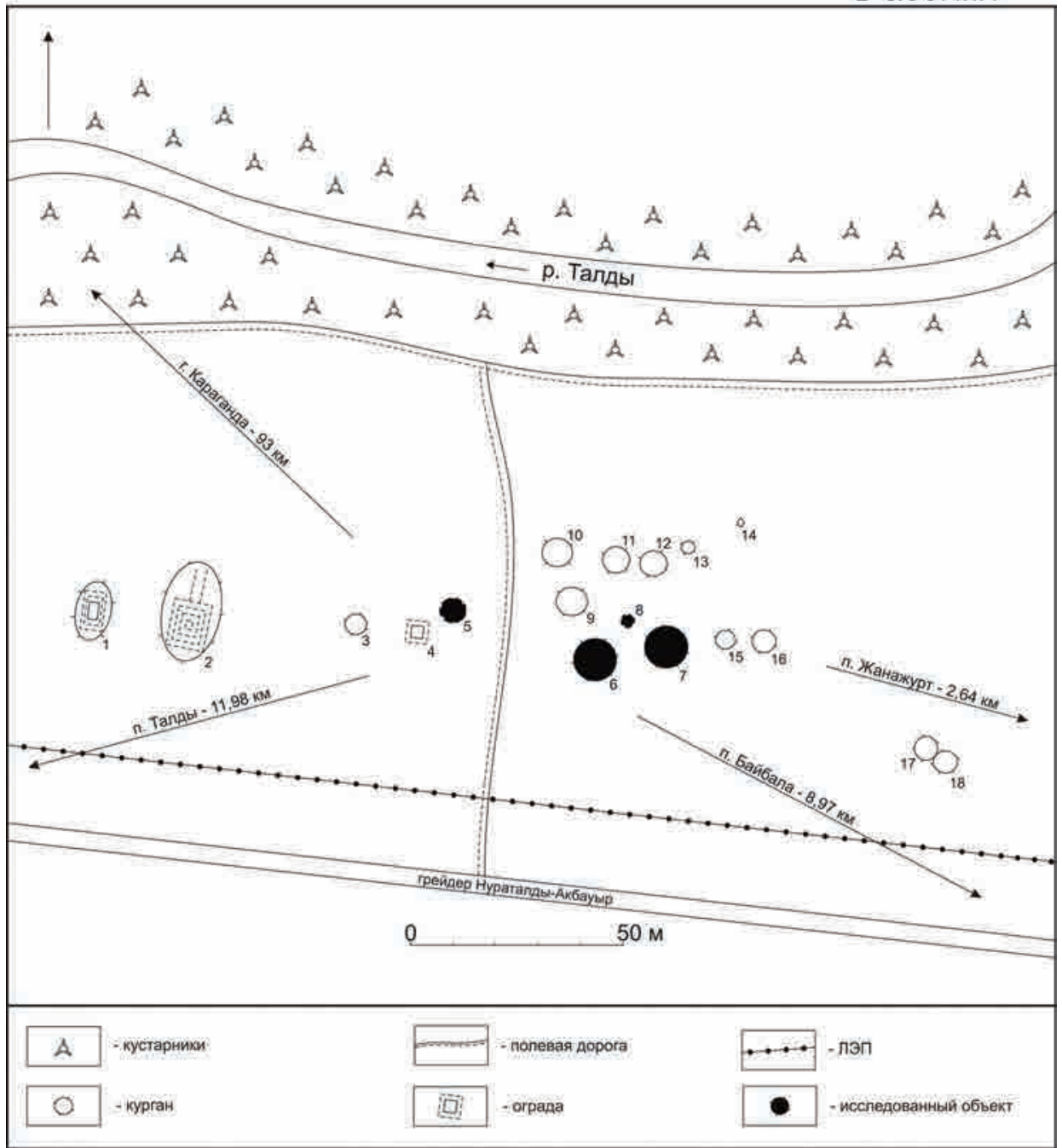

Рис. 1. Ситуационный план могильника Талдинский-1. Исполнитель: А.И. Кукушкин Fig. 1. Situational plan of the Taldinsky-1 burial ground. Realized Kukushkin A.I. 
го визуально зафиксированы отдельные плиты кольцевого ограждения диаметром 10,4 м, установленные на ребро (рис. 2). В процессе снятия насыпи в северной части западного сектора раскопа, на глубине 17 см от условного нуля, обнаружен металлический наконечник копья (рис. 3, 1), а также отдельные разрозненные кости крупного домашнего животного и фрагменты керамики от одного сосуда (выброшены при ограблении могилы) (рис. 4, 4). После снятия насыпи в центральной части подкурганной площадки выявлены границы погребальной камеры в виде грунтовой ямы размерами $3,1 \times 2,8$ м, ориентированной длинной осью по линии 3С3-ВЮВ (рис. 2).

При выборке заполнения могилы, на глубине 0,45 м от уровня материка, выявлены истлевшие фрагменты дерева, которые, вероятно, поддерживали перекрытие могилы, состоящее из плит, завалившихся внутрь. В заполнении, на разных уровнях, встречались человеческие кости двух индивидов (неопределенного пола возрастом до 16 лет и мужчины возрастом 20-25 лет) (определение пола и возраста выполнено Ингрид Чичюркайте, Вильнюсский университет), фрагменты керамики от четырех сосудов, а в придонном слое (на глубине 1 м) обнаружены металлические колечковидные бусины (рис. 3, 4), скоба, металлическое изделие (клин?), фрагменты желобчатого браслета, два каменных наконечника стрел, костяное навершие и подвеска из клыка животного (рис. 3, 4).

Металлический наконечник копья (рис. 3, 1) - имеет литую втулку, листовидное перо, ромбический в разрезе стержень и два боковых округлых сквозных отверстия по низу втулки, а также с одной из сторон отверстие, образовашееся в результате литейного брака. Общая длина изделия $-21,5$ см, длина пера - 12,5 см, максимальная ширина 4,8 см, длина втулки $-8,5$ см, диаметр по устью - 3 см (внешний) и 2,5 см (внутренний).

Металлическая скоба (рис. 3, 2) - длиной 5,3 см, изготовлена из подквадратного в сечении (0,4 см) прута металла. Имеет загнутые концы.

Металлическое изделие (клин?) (рис. 3, 3) - длиной 3,9 см, шириной до $1 \mathrm{~cm}$, толщиной до 0,6 см, подпрямоугольное в сечении. Имеет уплощенный рабочий край.

Костяное навершие (рис. 3, 5) - цилиндрической формы, длиной 2,7 см, округлое в разрезе (диаметр нижней части - 2,1 см, верхней 1,4 см). В верхней половине расположены четыре овальных отверстия, размерами $1 \times 0,7 \mathrm{~cm}$.

Каменный наконечник стрелы (рис. 4, 5 (см. левый)) - подтреугольной в плане формы $(4,7 \times 2,8 \times 0,35$ см), с прямым основанием, двояковыпуклый в сечении. Поверхность и края изделия отретушированы.

Каменный наконечник стрелы (рис. 4, 5 (см. правый)) - иволистной в плане формы $(5,4 \times 1,6 \times 0,7 \mathrm{~cm})$, со скругленным основанием, двояковыпуклый в сечении. Поверхность и края изделия отретушированы.

Сосуд 1 (рис. 4, 4) вертикальных пропорций, горшковидный, плечо отделено от тулова выраженным ребром. Шейка короткая, прямая, резко отогнутая наружу, по основанию подчеркнута узким заостренным валиком, завершается скругленным венчиком. Дно плоское. Под венчиком, изнутри, нанесена цепочка равносторонних наклонно заштрихованных треугольников, опущенных вер- 


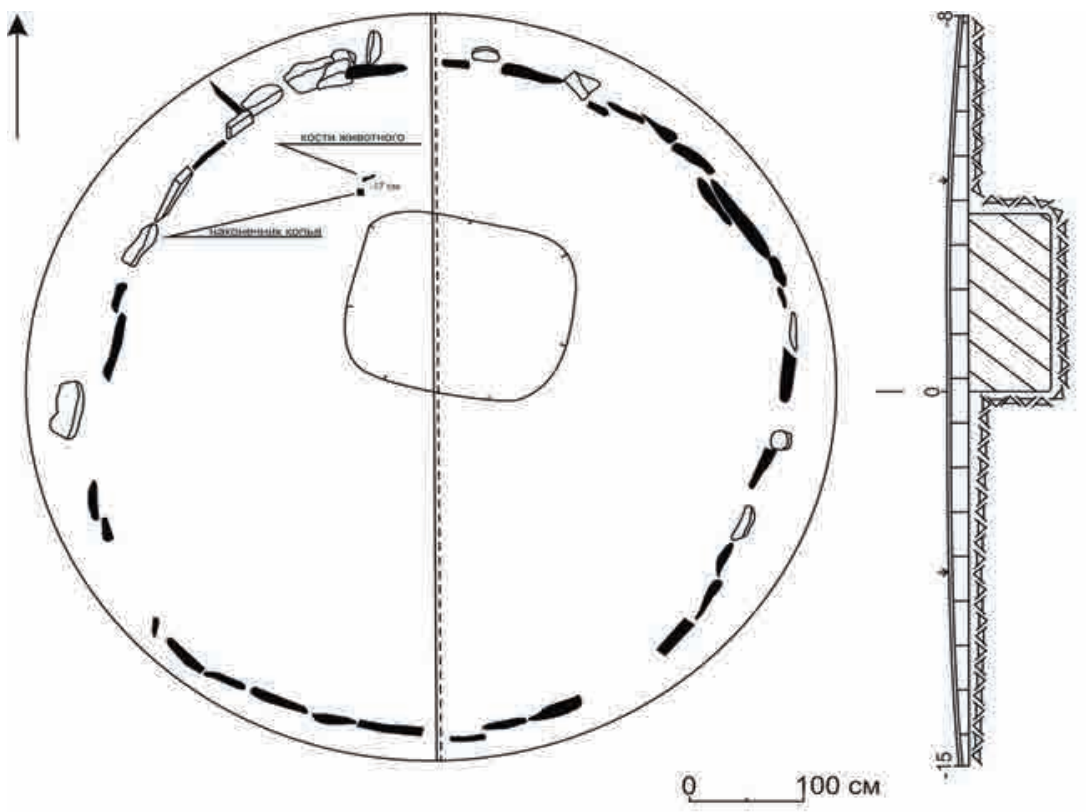

Условные обозначения:

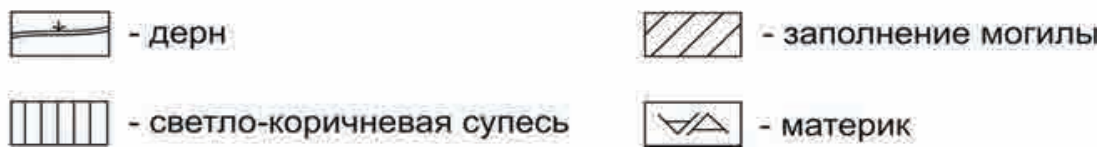

Рис. 2. План и профиль кургана 7 могильника Талдинский-1 Исполнитель: А.И. Кукушкин

Fig. 2. Plan and profile of the mound 7 of Taldinsky-1 burial ground Realized Kukushkin A.I.

шинами вниз. Под валиком изображены направленные вершинами друг к другу равносторонние наклонно заштрихованные треугольники, образовывавшие между собой свободную от рисунка зигзагообразную полосу в негативе. Ребро оконтурено двумя параллельными горизонтальными резными линиями, ниже которых нанесены треугольные фестоны. Орнамент выполнен гладким штампом. Диаметр устья - 24 см, плеча - 26 см, дна - 10 см. Общая высота сосуда составила $20 \mathrm{~cm}$.

Сосуд 2 (рис. 4, 2) горизонтальных пропорций, горшковидный, плечо отделено от тулова выраженным ребром. Шейка короткая, отогнутая наружу, по основанию подчеркнутая узким скругленным валиком, оканчивается скругленным венчиком. Дно плоское. Под венчиком имеется округлое сквозное отверстие (сосуд был частично реконструирован, поэтому судить о возможности наличия второго отверстия можно лишь гипотетически). Валик орнаментирован наклонными отрезками. Плечико покрыто равносторонними наклонно заштрихованными треугольниками, направленными вершинами вверх. Ребро оконтурено двумя каннелюрами, ниже которых, двумя каннелюрами образован валик с аналогичным 


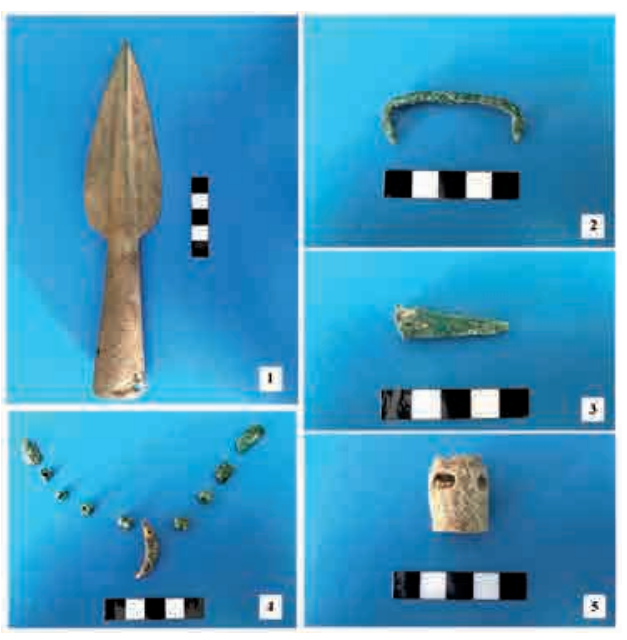

Рис. 3. Могильник Талдинский-1, курган 7. Находки. Фото Е.А. Дмитриева

Fig. 3. Taldinsky-1 burial ground, the mound 7. Findings. Photo by Dmitriev E.A.

узором. Тулово покрыто наклонно заштрихованными равносторонними треугольниками направленными вершинами вниз. Придонная часть имеет рисунок в виде наклонно заштрихованных равносторонних треугольников, направленных вершинами вверх. Основание узора подчеркнуто двумя каннелюрами, между которыми образовался валик с наклонными вправо отрезками. Рисунок, за исключением изображенного узора на валиках, выполнен мелкозубчатым штампом. Диаметр устья - 9 см, плеча - 11 см, дна -7 см. Общая высота сосуда составила 7 см.

Сосуд 3 (рис. 4, 1) горизонтальных пропорций, баночной формы (закрытая). Под уплощенным венчиком нанесены две каннелюры, ниже которых изображена горизонтальная «елочка», оконтуренная снизу каннелюрой. Нижняя половина тулова покрыта вертикальной «елочкой», разделенной горизонтальной линией. Причем верхние ряды рисунка, также как и выше изображенного узора, выполнены оттисками веревочки, а нижние - гладким штампом.

Сосуд 4 (рис. 4, 3) предположительно баночной формы. Имеет уплощенный венчик, ниже которого оттисками гладкого штампа нанесен узор.

Обнаруженный наконечник копья, согласно типологии Е.Н. Черных и С.В. Кузьминых, принадлежит к разряду КД-36 [Черных, Кузьминых, 1989, с. 80-81, рис. 47]. Данные наконечники хорошо известны по материалам петровских могильников Ащису (Центральный Казахстан) [Кукушкин И.А., 2011, рис. 2, 1], Бектениз (Северный Казахстан) [Зданович, 1983, с. 56], Кривое Озеро (Южное Зауралье) [Виноградов и др., 2017, рис. 108]. Все они характеризуются такими признаками, как листовидное перо, ромбический или округло-ромбический стержень, и отличаются от синташтинских изделий (Халвай III [Шевнина, Логвин, 2015, рис. 17, 1] Танаберген II, Жаман-

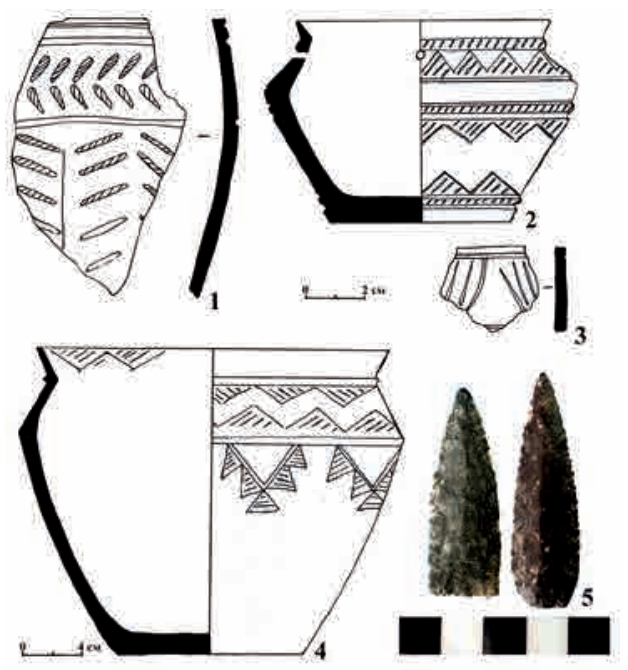

Рис. 4. Могильник Талдинский-1, курган 7. Находки. Фото Е.А. Дмитриева

Fig. 4. Taldinsky-1 burial ground, the mound 7. Findings.

Photo by Dmitriev E.A. 
Каргала 1 [Ткачев В.В., 2007б, рис. 9, 1 , рис. 23, 3] и др.) наличием цельнолитой втулки. Определенное сходство петровских наконечников копий можно обнаружить и с изделием из Ростовкинского клада [Дегтярева, Нескоров, 2015, рис. 1, 1], однако, имеется отличие в форме пера.

Не противоречат культурной атрибуции обнаруженные в кургане 7 могильника Талдинский-1 металлическая скоба, украшения и два каменные наконечника стрел с усеченным основанием, широко известные в петровских [Зданович, 1988, с. 138] и реже в синташтинских комплексах [Ткачев В.В., 2007б, с. 188].

Особо интересным представляется керамический комплекс сооружения 7. Горшковидные сосуды имеют ребро при переходе от шейки к тулову и характерный геометрический орнамент, что свойственно гончарной традиции петровцев [Зданович, 1983, с. 60]. К примеру, узор в виде вертикальной «елочки» с разделительными линиями можно назвать типичным для орнаментики [Кузьмина Е.Е., 2008, с. 98], имеющим близкие аналогии в посуде бабинской культуры [Смирнов, Кузьмина Е.Е., 1977, с. 29-32, рис. 9; Литвиненко, 2011 , рис. 3 , 32, $34,39,40$, рис. 5,29 , 34 , 35, рис. $6,28,31]$. В значительной степени архаичной выглядит и техника нанесения рисунка на одной из банок (рис. 4,1 ), представляющая собой оттиск веревочки. Наличие внутреннего ребра под венчиком на двух горшках характерно для абашевской и синташтинской посуды, исчезающей в последующее время [Ткачев В.В., 2007б, с. 271].

Аналогии миниатюрному сосуду со сквозными отверстиями (рис. 4 , 2) имеются в синташтинских древностях, где они предназначались для об- рядовой практики [Виноградов, 2011, с. 50,53 , рис. 14], являются «визитной карточкой абашевской культуры» [Кузьмина О.В., 1992, с. 22]. В Центральном Казахстане известен только один такой сосуд, происходящий из могильника Сатан [Евдокимов, 1981].

В хронологическом плане еще Г.Б. Здановичем было отмечено, что в Центральном Казахстане известны только позднепетровские памятники, а в качестве погребальных камер использовались преимущественно каменные ящики [Зданович, 1988, с. 136]. Идея различия между северо-казахстанскими и центрально-казахстанскими памятниками была хорошо проработана А.А. Ткачевым, который на основании некоторых специфических признаков выделил самостоятельную нуртайскую культуру [Ткачев А.А., 1999]. Думается, петровцы появляются в регионе довольно рано, о чем могут свидетельствовать некоторые синташтинские реминисценции в металле [Кукушкин И.А., 2007, с. 46], гончарстве (внутреннее ребро, некоторая абашоидная вуаль в керамике Талдинского-1, нанесение орнамента веревочкой), а сделанные ранее выводы базировались на имевшемся в то время фактическом материале. В этом ракурсе хотелось бы выдвинуть еще одно предположение (которое, как и вышесказанное требует проведения основательной аналитической работы в данном направлении). На горшечных сосудах сооружения 7 могильника Талдинский-1 в месте перехода от шейки к плечику имеется перегиб, что принципиально отличает от известных авторам материалов Центрального Казахстана, где ранее известен был плавно изогнутый переход (к примеру, экземпляры, 
проиллюстрированные в работах: Ткачев А.А., 1999; Кукушкин И.А. и др., 2016). Эта особенность посуды, обнаруженной в кургане 7 , более характерна для синташтинских сосудов [Генинг и др., 1992, рис. 32, 1-8, 10, 13 и т.д.; Аркаим ..., 2002, рис. 20, 6; 24,$3 ; 25,2,5$ и т.д.]. Думается, посуда с резким перегибом характерна для раннепетровских памятников региона, а со сглаженным плавным переходом - для поздних (нуртайских по А.А. Ткачеву), соответствующих кулевчинской петровке сопредельных территорий [Кукушкин И.А., Дмитриев, 2018, с. 36].

Необходимо также обратить внимание на определенный разнобой в терминологии раннеандроновского периода. С нашей позиции, такие дефиниции как петровский и раннеалакульский, взаимозаменяемы и синонимичны друг другу, как, например, покровские и раннесрубные древности. В свою очередь, кулевчинские памятники могут быть соотнесены с позднепетровским временем или с завершающим этапом раннеалакульской стадии развития культуры. Актуальность данной конкретизации определяется также размытостью границ между поздней петровкой/ ранним алакулем и собственно алакулем, где материалы памятников зачастую могут совмещать признаки как раннего алакуля в его поздней стадии, так и характеристики классического периода.

Таким образом, полученный в ходе исследования сооружения 7 могильника Талдинский-1 материал, безусловно, дал новые сведения о ранней истории андроновских племен Центрального Казахстана. Выдвинутые в рамках данной статьи предположения требуют основательной проверки, а сама работа является лишь первым шагом по введению в научный оборот неопубликованных раннепетровских материалов региона, накопленных в ходе исследований последних пяти лет.

Работа выполнена при финансовой поддержке Комитета науки Министерства образования и науки Республики Казахстан (ИРН проекта АР05131774).

\section{ЛИТЕРАТУРА}

1. Аркаим: некрополь (по материалам кургана 25 Большекараганского могильника) / Сост. Д.Г. Зданович. Челябинск: Юж.-Урал. кн. изд-во, 2002. Кн. 1. 216 с.

2. Виноградов Н.Б. Степи Южного Урала и Казахстана в первые века II тыс. до н.э. (памятники синташтинского и петровского типа). Челябинск: Абрис, 2011. 175 c.

3. Виноградов Н.Б., Дегтярева А.Д., Кузьминых С.В., Медведева П.С. Могильник бронзового века Кривое Озеро в Южном Зауралье. Челябинск: АБРИС, 2017. $400 \mathrm{c}$.

4. Генинг В.Ф., Зданович Г.Б., Генинг В.В. Синташта: археологические памятники арийских племен Урало-Казахстанских степей. Челябинск: Юж.-Урал. кн. издBо, 1992.408 c.

5. Дегтярева А.Д., Нескоров А.В. Ростовкинский клад бронзовых изделий эпохи бронзы (культурная интерпретация) // ВААЭ. 2015. № 3 (30). С. 32-41.

6. Евдокимов В.В. Отчет об археологических исследованиях на территории Карагандинской области летом 1980 года. Караганда, 1981. Архив Сарыаркинского археологического института: оп. 2, д. 1827.139 с. 
7. Зданович Г.Б. Основные характеристики петровских комплексов УралоКазахстанских степей (к вопросу о выделении петровской культуры) // Бронзовый век степной полосы Урало-Иртышского междуречья. Межвузовский сборник. Уфа: Изд-во Башкирского ун-та, 1983. С. 48-68.

8. Зданович Г.Б. Бронзовый век Урало-Казахстанских степей (основы периодизации). Свердловск: изд-во Урал. ун-та, 1988. 184 с.

9. Кузьмина E.E. Классификация и периодизация памятников андроновской культурной общности. Актобе: ПринтА, 2008. 358 с.

10. Кузьмина O.В. Абашевская культура в лесостепном Волго-Уралье: учебное пособие. Самара: изд-во Самарского гос. ун-та, 1992. 128 с.

11. Кукушкин И.А. Могильник Аяпберген - раннеандроновский памятник Центрального Казахстана // Изучение памятников археологии Павлодарского Прииртышья. Павлодар: НПФ «ЭКО», 2006. Вып. 2. С. 50-69.

12. Кукушкин И.А. Археологические исследования могильника Ащису. Курган 1 // Историко-культурное наследие Сарыарки. Караганда: изд-во КарГУ, 2007. С. 40-64.

13. Кукушкин И.А. Металлические изделия раннеандроновского могильника Ащису (Центральный Казахстан) // РА. 2011. № 2. С. 103-109.

14. Кукушкин И.А., Дмитриев Е.А. Раннеалакульские древности могильника Танабай (по материалам кургана 4) // ВААЭ. 2018. № 2 (41). С. 28-40.

15. Кукушкин И.А., Ломан В.Г., Кукушкин А.И., Дмитриев Е.А. Погребение с металлическим сосудом в могильнике Нураталды I (эпоха бронзы) // Уральский исторический вестник. 2016. № 4 (53). С. 85-92.

16. Литвиненко Р.А. Культурный круг Бабино: название, таксономия и структура // КСИА. 2011. Вып. 225. С. 108-123.

17. Смирнов К.Ф., Кузьмина Е.Е. Происхождение индоиранцев в свете новейших археологических открытий. М.: Наука, 1977. 82 с.

18. Ткачев A.A. Особенности нуртайских комплексов Центрального Казахстана // ВААЭ. 1999. № 2. С. 22-29.

19. Ткачев А.А. Центральный Казахстан в эпоху бронзы. Тюмень: ТюмГНГУ, 2002. Ч. 1. 289 c.

20. Ткачев B.В. К вопросу о памятниках нуртайского типа Центрального Казахстана // Кадырбаевские чтения: матер. междунар. научн. конф. Под ред. А.А. Бисембаева. Актобе: ПринтА, 2007а. С. 41-44.

21. Ткачев B.B. Степи Южного Приуралья и Западного Казахстана на рубеже эпох средней и поздней бронзы. Актобе: Актюбинский областной центр истории, этнографии и археологии, 2007б. 384 с.

22. Черных E.H., Кузьминых С.В. Древняя металлургия Северной Евразии (сейминско-турбинский феномен). М.: Наука, 1989. 320 с.

23. Шевнина И.В., Логвин А.В. Могильник эпохи бронзы Халвай III в Северном Казахстане. Материалы и исследования по археологии Казахстана. T. VII. Астана: филиал Института археологии им. А.Х. Маргулана, 2015. 248 с.

\section{Сведения об авторах:}

Жауымбай Сагындык Убайұлы - кандидат исторических наук, профессор кафедры Археологии, этнологии и отечественной истории, КарГУ им. академика Е.А. Букетова (г. Караганды, Казахстан)

Кукушкин Игорь Алексеевич - ведущий научный сотрудник, Сарыаркинский археологический институт, КарГУ им. академика Е.А. Букетова (г. Караганды, Казахстан); sai@ksu.kz

Кукушкин Алексей Игоревич - докторант $\mathrm{PhD}$, КарГУ им. академика E.А. Букетова (г. Караганды, Казахстан); tatarlandia@mail.ru

Дмитриев Евгений Анатольевич - младший научный сотрудник, Сарыаркинский археологический институт, КарГУ им. академика Е.А. Букетова (г. Караганды, Казахстан); уevgenii1992@mail.ru

Шохатаев Олжас Саятович - PhD, старший преподаватель кафедры Истории Казахстана, КарГУ им. академика Е.А. Букетова (г. Караганды, Казахстан) 


\title{
ОРТАЛЫҚ ҚАЗАҚСТАНДАҒЫ АНДРОНОВ ТАЙПАЛАРЫНЫН ЕРТЕ ТАРИХЫ ТУРАЛЫ ЖАНА МӘЛІМЕТТЕР \\ (Талды 1 қабірі 7 қорғанның материалдары бойынша)
}

\author{
С.У. Жауымбай, И.А. Кукушкин, А.И. Кукушкин, \\ Е.А. Дмитриев, О.С. Шохатаев
}

Аталған мақала шеңберінде ғылыми айналымға ҚарМУ археологиялық экспедициясымен 2018 ж. Талды-1 қорымындағы 7-ші қорғанға жасалған зерттеу нәтижелері кіргізіледі. Орталық Қазақстан территориясындағы андронов тайпаларының ерте тарихы туралы жаңа мәліметтер алынды. Ескерткіш Қарағанды облысының Шет ауданында, Талды к. 12 км шығыс-солтүстік-шығысқа қарай, Талды ө. оң жағалауындағы салыстырмалы түзу алаңда орналасқан, онда көзге көрінетін екі мәдени-хронологиялық көкжиектің 18 құрылысы тіркелген: ертеандрондық (петровтық / ертеалакөлдік типтегі) және соңғықолалық (беғазы-дәндібайлық типтегі). Қыстық материал, авторлардың пікірінше, петровтық мәдениеттің ерте кезеңін сипаттайды (ол ішкі қабырғасы тәжік астында екенін, суреті жіпше, ғұрыптық ыдысы абашоидтік кескінде екенін, ірі жер шұңқырларының және жерлеу құралдарының бар екенін көрсетеді). Өңірде тек соңғы кезеңнің ескерткіштерінің бары туралы тұрып қалған пікірге қарсы салмақ ретінде, аргументтелген болжамды көзқарас шығарылып жатыр, демек, жинақталған ертеандрондық материалдар петров мәдениетін екі кезеңге бөлуге мүмкіндік береді: ерте (яғни петровтық) және соңғы (кулевчиндікке ұқсас), ол қыштық кешенде және заттық құрал-жабдықтарда көрсетілген.

Түйін сөздер: археология, Орталық Қазақстан, қола дәуірі, петров мәдениеті, найзаның ұшы, қыштық кешен, ғұрыптық ыдыс

\section{NEW INFORMATION ABOUT THE EARLY HISTORY OF THE ANDRONIAN TRIBES OF CENTRAL KAZAKHSTAN \\ (based on the materials of the mound 7 of Taldinsky-1 burial ground)}

\section{S.U. Jauymbay, I.A. Kukushkin, A.I. Kukushkin, E.A. Dmitriev, O.S. Shokhatayev}

Within the framework of this article, the results of the studies carried out on the mound 7 of the Taldinskiy-1 burial ground in 2018 by the archaeological expedition of the Karaganda State University are introduced into the scientific circulation. New information about the early history of Andronovo tribes in the territory of Central Kazakhstan is obtained. The monument is located in the Shetsky district of the Karaganda region, 93 $\mathrm{km}$ southeast of the city of Karaganda, $12 \mathrm{~km}$ east-northeast of the village of Taldy and is located on a relatively flat area on the left bank of the river. Taldy, on which 18 structures of two cultural-chronological horizons were visually fixed: the early Andronovo (Petrovo / early Alakul type) and the late bronze (Begazy-Dandybaev type) horizons. Ceramic material, according to the authors, characterizes the early stage of Petrovsky culture (which is reflected in the presence of an internal rib under the whisk, patterning with a rope, Abashevo appearance of a ritual vessel, the presence of a large soil pit and funeral equipment). In contrast to the established opinion on the presence of only the late-stage monuments in the region, a well-founded assumption is advanced that the accumulated early Andronovo materials can be divided into two stages of Petrovo culture: early (Petrovo) and late (similar to Kulevchinsky), which is reflected in the ceramic complex and objects inventory.

Keywords: archaeology, Central Kazakhstan, Bronze Age, Petrovo culture, spearhead, ceramic complex, ritual vessel 


\section{REFERENCES}

1. Zdanovich, D. G. (ed.). 2002. Arkaim: nekropol' (po materialam kurgana 25 Bol'shekaraganskogo mogil'nika) (Arkaim: necropolis (according to the materials of the mound 25 of the Bolshekaragansky burial ground)). Chelyabinsk: Yuzh.-Ural. kn. Publ., vol. 1. (in Russian).

2. Vinogradov, N. B. 2011. Stepi Yuzhnogo Urala i Kazakhstana v pervye veka II tys. do n.e. (pamyatniki sintashtinskogo i petrovskogo tipa) (The steppes of the Southern Urals and Kazakhstan in the first centuries of the 2nd millennium BC. (monuments of Sintashta and Petrovsky type)). Chelyabinsk: "Abris» Publ. (in Russian).

3. Vinogradov, N. B., Degtyareva, A. D., Kuz'minykh, S. V., Medvedeva, P. S. 2017. Mogil'nik bronzovogo veka Krivoe Ozero v Yuzhnom Zaural'e (Burial ground of Krivoe Lake of the Bronze Age in the Southern Trans-Urals). Chelyabinsk: "ABRIS» Publ. (in Russian).

4. Gening, V. F., Zdanovich, G. B., Gening, V. V. 1992. Sintashta: arkheologicheskie pamyatniki arijskikh plemen Uralo-Kazakhstanskikh stepej (Sintashta: archaeological sites of the Aryan tribes of the Ural-Kazakhstan steppes). Chelyabinsk: Yuzh-Ural. kn. Publ.. (in Russian).

5. Degtyareva, A. D., Neskorov, A. V. 2015. In Vestnik arkheologii, antropologii $i$ ehtnografii (Bulletin of archaeology, anthropology and ethnography), 3(30), 32-41 (in Russian).

6. Evdokimov, V. V. 1981. Otchet ob arkheologicheskikh issledovaniyakh na territorii Karagandinskoj oblasti letom 1980 goda. (Report on the archaeological research in the Karaganda region in the summer of 1980). Karaganda. Archive of the Saryarka Archaeological Institute, op. 2, d. 1827 (in Russian).

7. Zdanovich, G. B. 1983. In Bronzovyi vek stepnoj polosy Uralo-Irtyshskogo mezhdurech'ya. Mezhvuzovyj sbornik (The Bronze Age of the steppe belt of the UralIrtysh interfluve. Interuniversity collection). Ufa: Bashkirsk. University Publ., 48-68 (in Russian).

8. Zdanovich, G. B. 1988. Bronzovyj vek Uralo-Kazakhstanskikh stepej (osnovy periodizatsii) (The Bronze Age of the Ural-Kazakhstan steppes (the foundations of periodization)). Sverdlovsk: Ural. university Publ. (in Russian).

9. Kuz'mina, E. E. 2008. Klassifikatsiya i periodizatsiya pamyatnikov andronovskoj kul'turnoj obshhnosti (Classification and periodization of the monuments of the Andronovo cultural community). Aktobe: «PrintA» Publ. (in Russian).

10. Kuz'mina, O. V. 1992. Abashevskaya kul'tura v lesostepnom Volgo-Ural'e: uchebnoe posobie (Abashevskaya culture in the forest-steppe Volga-Ural region: a textbook). Samara: Samara State University Publ. (in Russian).

11. Kukushkin, I. A. 2006. In Merts, V. K. (Ed.) Izuchenie pamyatnikov arkheologii Pavlodarskogo Priirtysh 'ya (Study of the archaeological monuments of Pavlodar Irtysh). Pavlodar: NPF «EHKO» Publ., 2, 50-69 (in Russian).

12. Kukushkin, I. A. 2007. In Istoriko-kul'turnoe nasledie Saryarki (Historical and cultural heritage of Saryarka). Karaganda, 40-64 (in Russian).

13. Kukushkin, I. A. 2011. In Rossijskaya arkheologiya (Russian archeology), 2, 103-109 (in Russian).

14. Kukushkin, I. A., Dmitriev, E. A. 2018. In Vestnik arkheologii, antropologii $i$ ehtnografii (Bulletin of archeology, anthropology and ethnography), 2 (41), 28-40 (in Russian).

15. Kukushkin, I. A., Loman, V. G., Kukushkin, A. I., Dmitriev, E. A. 2016. In Ural 'skij istoricheskij vestnik (Ural Historical Bulletin), 4 (53), 85-92 (in Russian).

16. Litvinenko, R. A. 2011. In Kratkie soobshheniya Instituta arkheologii (Brief reports of the Institute of Archeology), 225, 108-123 (in Russian).

17. Smirnov, K. F., Kuz'mina, E. E. 1977. Proiskhozhdenie indoirantsev v svete novejshikh arkheologicheskikh otkrytij (The origin of the Indo-Iranians in the light of the latest archaeological discoveries). Moscow: «Nauka» Publ. (in Russian). 
18. Tkachev, A. A. 1999. In Vestnik arkheologii, antropologii i ehtnografii (Bulletin of archeology, anthropology and ethnography), 2, 22-29 (in Russian).

19. Tkachev, A. A. 2002. Tsentral 'nyj Kazakhstan v epohu bronzy (Central Kazakhstan in the Bronze Age), p. 1. Tyumen": "TyumGNGU» Publ. (in Russian).

20. Tkachev, V. V. 2007a. In Bisembaev, A. A. (ed.) Kadyrbaevskie chteniya (Kadyrbayev readings). Aktobe: «PrintA» Publ., 41-44 (in Russian).

21. Tkachev, V. V. 2007b. Stepi Yuzhnogo Priural'ya i Zapadnogo Kazakhstana na rubezhe ehpokh srednej i pozdnej bronzy (The steppes of the Southern Urals and Western Kazakhstan at the turn of the Middle and Late Bronze Age). Aktobe (in Russian).

22. Chernykh, E. N., Kuz'minykh, S. V. 1989. Drevnyaya metallurgiya Severnoj Evrazii (sejminsko-turbinskii fenomen) (Ancient metallurgy of Northern Eurasia (SeimaTurbian phenomenon)). Moscow: «Nauka» Publ. (in Russian).

23. Shevnina, I. V., Logvin, A. V. 2015. Mogil'nik epohi bronzy Halvay III v Severnom Kazahstane. Materialy $i$ issledovaniya po arkheologii Kazakhstana (The cemetery of the Bronze Age Halvay III in Northern Kazakhstan. Materials and research on the archeology of Kazakhstan), vol. VII. Astana Publ., (in Russian).

\section{About the Authors:}

Jauymbay Sagyndyk U. Candidate of historical sciences, professor of the Department of Archeology, Ethnology and National History, Karagandy State University of the name of academician Ye.A. Buketov, Karagandy, Kazakhstan

Kukushkin Igor A. Leading Researcher, Saryarka Archaeological Institute, Karagandy State University of the name of academician Ye.A. Buketov, Karagandy, Kazakhstan; sai@ksu.kz

Kukushkin Alexey I. PhD doctoral student, Karagandy State University of the name of academician Ye.A. Buketov, Karagandy, Kazakhstan; tatarlandia@mail.ru

Dmitriev Evgeniy A. Junior researcher, Saryarka Archaeological Institute, Karagandy State University of the name of academician Ye.A. Buketov, Karagandy, Kazakhstan; yevgenii1992@mail.ru

Shokhatayev Oljas S. Senior lecturer, Department of History, Karagandy State University of the name of academician Ye.A. Buketov, Karaganda, Kazakhstan

\footnotetext{
Мүдделер қақтығысы туралы ақпаратты ашу. Авторлар мүдделер қақтығысының жоқтығын мәлімдейді. / Раскрытие информации о конфликте интересов. Авторы заявляют об отсутствии конфликта интересов. / Disclosure of conflict of interest information. The authors claims no conflict of interest. 